\title{
Clinical Feature Difference of Children and Adults in Covid-19 Infected Family Clusters in Shenzhen China: A Retrospective Cohort Study
}

\author{
Peize Zhang ${ }^{1,3 \dagger}$, Jianfeng Zeng ${ }^{1,3 \dagger}$, Jianbin $\mathrm{Wu}^{2 \dagger}$, Yuxiang Wang ${ }^{1,3}$, Liang $\mathrm{Fu}^{1,3}$, Tao Chen ${ }^{1,3}$, Hailin \\ Zhang $^{1,3}$ and Guofang Deng*1,4 \\ ${ }^{1}$ Department of Pulmonary Medicine and Tuberculosis, Shenzhen, Guangdong, China
}

${ }^{2}$ Department of Oncology, The First Affiliated Hospital of Guangzhou University of Chinese Medicine, Guangzhou 510407, China

${ }^{3}$ National Clinical Research Center for Infectious Disease, Shenzhen, China

*Corresponding author: Guofang Deng, Department of Pulmonary Medicine and Tuberculosis, The Third People's

Hospital of Shenzhen, No. 29 Bulan Road, Longgang District, Shenzhen, Guangdong, China

\section{ARTICLE INFO}

Received: 慧 September 11, 2020

Published: 幽 September 22, 2020

Citation: Peize Zhang, Jianfeng Zeng, Jianbin $\mathrm{Wu}$, Yuxiang Wang, Liang Fu, Tao Chen, Hailin Zhang, Guofang Deng. Clinical Feature Difference of Children and Adults in Covid-19 Infected Family Clusters in Shenzhen China: A Retrospective Cohort Study. Biomed J Sci \& Tech Res 30(4)-2020. BJSTR. MS.ID.004977.

Abbreviations: COVID-19: Novel Coronavirus Disease 2019; SARS-CoV-2: Severe Acute Respiratory Syndrome Coronavirus 2; MERS-CoV: Middle East Respiratory Syndrome Coronavirus; SARS: Severe Acute Respiratory Syndrome; MERS: Middle East Respiratory Syndrome; RT-PCR: Reverse Transcription Polymerase Chain Reaction; CT: Computer Tomography; RNA: Ribonucleic Acid; PaO2: Arterial Oxygen Tension; FiO2: Inspiratory Oxygen Fraction; SD: Standard Deviation; IQR: Interquartile Range; CRP: C-reactive Protein; ARDS: Acute Respiratory Distress Syndrome

\section{ABSTRACT}

Introduction: An outbreak of novel coronavirus disease (COVID-19) had posed an unprecedented emergency to public health. Documented information on clinical features in infected households comprising pediatric and adult patients was scarce.

Methods: We retrospectively retrieved clinical data of family clusters with confirmed COVID-19 in Shenzhen city, China. Clinical features and treatment outcome were compared between these children and adults.

Results: Of 433 laboratory-confirmed COVID-19 cases in Shenzhen from January 15 to March 20, 2020, 29 family clusters of 29 children (median age 7.17 years) and 54 adults (median age 40 years) were identified. $84 \%$ of patients had Hubei exposure two weeks before the onset of symptoms. On presentation, common symptoms were fever $(35 \%)$, dry cough $(34 \%)$ and fatigue $(24 \%)$ for children and fever $(59 \%)$, dry cough (30\%), fatigue $(30 \%)$ and dyspnea (20\%) for adults. Lymphocytopenia was not observed in children but $35 \%$ adults. Radiographic findings revealed viral pneumonia in $45 \%$ children and $78 \%$ adults. No children and $30 \%$ adults needed oxygen therapy. Two adults required invasive mechanical ventilation, of them one died. The median time from illness onset to absence of symptoms and viral replication duration was 6.5 days vs 13 days, and 12 days vs 14 days in children and adults, respectively.

Interpretation: In comparison to adults, children had milder clinical manifestations, less immune-related organ injury and shorter viral replication cycle. The age-specific immune difference seems to favor children more in developing less severe clinical conditions and clearing the virus faster.

Keywords: COVID-19; Pediatrics; Clinical Features; Family Clusters; SARS-CoV-2; Family Infection

\section{Introduction}

An outbreak of a novel coronavirus disease (COVID-19, previously known as 2019-nCoV) was reported in Wuhan, Hubei Province of China in December 2019 and later evolved into a pandemic and threatened the lives of many across the globe. COVID-19 is caused by the severe acute respiratory syndrome coronavirus 2 (SARS-CoV-2) which belongs to the Coronaviridae 
family [1]. Most coronavirus infections in children used to be mild and were able to be resolved quickly, even in cases of severe illness caused by Middle East respiratory syndrome coronavirus (MERS$\mathrm{CoV}$ ) and severe acute respiratory syndrome coronavirus (SARS$\mathrm{CoV}$ ). Most reported fatal cases in children with MERS and SARS were caused by underlying comorbidities [2-4]. Numerous studies of COVID-19 infection among infants and children have been reported since the outbreak [5-8], but no studies have compared the clinical and virological course and treatment outcomes among pediatric and adult patients in infected household settings. In this study, we retrospectively analyzed the clinical course and treatment outcome of all laboratory-confirmed COVID-19 family clusters from Jan 15, 2019 to Mar 20, 2020 in Shenzhen City, China. We aim to describe the clinical difference between children and their simultaneously SARS-CoV-2-infected adult family members. We hope our study findings can provide some insights in clinical management of infected pediatric and adult patients, and disease containment measure for COVID-19.

\section{Methods}

\section{Study Design and Participants}

Shenzhen is a city of 12.5 million registered population in 2017 and is located at Southern China [9]. From January 15 to March 20, 2020, 433 patients with laboratory-confirmed COVID-19 were admitted to The Third People's Hospital of Shenzhen, the only designated hospital for COVID-19 treatment in the city. Among these patients, 83 ( 29 children $\leq 14$ years and 54 adults) were family infections, accounting for $19 \%$ of the total confirmed infection in the city. Each child was residing with at least one infected adult parent. Some of these households had three generations living under the same roof and being infected together. This retrospective cohort study enrolled these 29 families. The study was approved by the Research Ethics Commission of The Third People's Hospital of Shenzhen (No.2020-120) and the requirement for informed consent was waived by the Ethics Commission as part of a public health outbreak investigation.

\section{Data Collection}

These patient's epidemiology linkage to Hubei province, sociodemographic characteristics, medical history, clinical features, comorbidities, complications, hospital duration and treatment outcomes were retrospectively collected using a standardized data collection form. All data were checked by two physicians (PZ and ZZ) and a third researcher (JW). Exposure to Hubei province, the place where the COVID-19 epidemic started was defined as residing in or visiting Hubei or have close contact with visitors from Hubei within two weeks before the onset of infection symptoms. Clinical features were reported in the form of symptoms at admission, clinical type classification, diagnosis, chest imaging and laboratory findings. Treatment outcomes were recorded as cured and death.

\section{Laboratory Procedures}

Nasopharyngeal swabs were collected for diagnosis at admission. Reverse transcriptionpolymerase chain reaction (RTPCR) testing was performed according to the recommended protocol to detect SARS-CoV-2. Diagnosis of infection was confirmed when positive test results were attained from both hospital laboratory and local branches of the Centers for Disease Control and Prevention.Blood examinations and chest radiographs were routine procedures and were completed at admission. Tests were arranged for all patients on blood cell count, serum biomarkers (including renal and liver function and electrolytes), D-Dimer, C-reactive protein and procalcitonin. Frequency of re-examinations was determined by the treating physician. Throat-swab specimens were obtained for SARS-CoV-2 RT-PCR re-examination every other day after symptoms remission. The criteria for hospital discharge were absence of fever and respiratory symptoms for at least three days, substantial improvement in both lungs in X-ray or chest CT, and two throat-swab samples and one anus-swab sample negative for SARS-CoV-2 RNA obtained at least $24 \mathrm{~h}$ apart.

\section{Definitions}

Children are defined as below 18 years of age. Fever is defined as axillary temperature of equal to or above $37 \cdot 3^{\circ} \mathrm{C}$. On admission, all patients were assessed and classified into one of these four clinical types according to the Chinese management guideline for COVID-19 (version 6.0) [10]. Critical type is used to classify patients who need intubation and mechanical ventilation, with sepsis or septic shock; severe type is used to classify patients whose arterial oxygen tension $\left(\mathrm{PaO}_{2}\right)$ over inspiratory oxygen fraction $\left(\mathrm{FiO}_{2}\right)$ is less than $300 \mathrm{~mm} \mathrm{Hg}\left(\mathrm{PaO}_{2} / \mathrm{FiO}_{2}<300 \mathrm{~mm} \mathrm{Hg}\right)$ and need oxygen therapy and invasive ventilation; moderate type refers to patients with flu symptom with lung infiltration but $\mathrm{PaO}_{2} / \mathrm{FiO}_{2}>300$; mild type refers to patients with flu symptom without lung infiltration. Lymphocytopenia is defined as lymphocyte count of less than $1.1 * 10^{9} / \mathrm{L}$.

\section{Statistical Analysis}

Continuous variables are expressed as mean $( \pm$ SD) and median (interquartile range [IQR]) values, and they are then tested using an unpaired test and the Wilcoxon rank sum test, respectively. Categoric data are expressed as number and percentages and are compared by $\chi^{2}$ test or Fisher's exact test between children and adults. A two-tailed $\alpha<0.05$ is considered to denote statistical significance. Statistical software (SPSS, version 22.0, SPSS) is used for all analyses.

\section{Results}

\section{Difference in Clinical Features Between Children and Adults}

Median age was 7.17 years (IQR 1.58-13.0) for the 29 children and 40.0 years (IQR 34.0-57.0) for the 54 adults in this cohort. 
Female accounted for 59\% of pediatric patients and 54\% adult patients, showing no distinctive gender difference. 24 (83\%) children and 46 (85\%) adults had exposure to the epicenter, Hubei province two weeks before illness onset, reflecting a rather straightforward transmission route. On admission, 19 (65\%) children had no fever; over half (59\%) of adults had fever and among them six $(11 \%)$ recorded an auxiliary temperature of over $39^{\circ} \mathrm{C}$. Common symptoms presented by children were fever (35\%), dry cough (34\%) and fatigue (24\%); and that of adults were fever (59\%), dry cough (30\%), fatigue (30\%) and dyspnea (20\%). In terms of comorbidities, one (3\%) child had asthma and one (3\%) had chronic pharyngitis, seven $(13 \%)$ adults suffered from diabetes and five (9\%) from hypertension. In terms of clinical type classification, all children were in the mild and moderate categories. $69 \%$ adults were classified as moderate, $19 \%$ severe, $2 \%$ critical. Significant difference was shown between children and adults in clinical type categorization ( $\mathrm{P}=0.004)$ (Table 1$)$.

Table 1: Demographics and baseline characteristics of the 29 family clusters infected with novel coronavirus disease 2019 (COVID-19).

\begin{tabular}{|c|c|c|c|c|}
\hline & All patients $(n=83)$ & $<18(n=29)$ & $\geq 18(n=54)$ & P Value \\
\hline Age, median (interquartile), y: & $34(10.58-45)$ & $7.17(4.75-10.8)$ & $40(34-57)$ & $<.001$ \\
\hline Sex: & & 0.667 & & \\
\hline Female & $46(55 \%)$ & $17(59 \%)$ & $29(54 \%)$ & \\
\hline Male & $37(45 \%)$ & $12(41 \%)$ & $25(46 \%)$ & \\
\hline Hubei exposure within 2 weeks: & $70(84 \%)$ & $24(83 \%)$ & $46(85 \%)$ & 0.772 \\
\hline \multicolumn{5}{|l|}{ Signs and symptoms } \\
\hline \multirow{2}{*}{ Auxiliary temperature $\left.\left({ }^{\circ} \mathrm{C}\right)\right):<37.3$} & & & & 0.085 \\
\hline & $41(49 \%)$ & $19(65 \%)$ & $22(41 \%)$ & \\
\hline \multicolumn{4}{|l|}{ Fever (Highest temperature $\left({ }^{\circ} \mathrm{C}\right)$ ): } & \\
\hline $37.3-38.0$ & $24(29 \%)$ & $6(21 \%)$ & $18(33 \%)$ & \\
\hline $38.1-39.0$ & $12(14 \%)$ & $4(14 \%)$ & $8(15 \%)$ & \\
\hline$>39.0$ & $6(7 \%)$ & 0 & $6(11 \%)$ & \\
\hline Dry cough & $26(31 \%)$ & $10(34 \%)$ & $16(30 \%)$ & 0.65 \\
\hline Fatigue & $23(28 \%)$ & $7(24 \%)$ & $16(30 \%)$ & 0.594 \\
\hline Nasal Congestion & $13(16 \%)$ & $3(10 \%)$ & $10(19 \%)$ & 0.509 \\
\hline Runny nose & $13(16 \%)$ & $5(17 \%)$ & $8(15 \%)$ & 0.772 \\
\hline Pharyngalgia & $11(13 \%)$ & $3(10 \%)$ & $8(15 \%)$ & 0.816 \\
\hline Myalgia & $13(16 \%)$ & $3(10 \%)$ & $10(19 \%)$ & 0.509 \\
\hline Diarrhea & $2(2 \%)$ & 0 & $2(4 \%)$ & 0.54 \\
\hline Anorexia & $9(11 \%)$ & $5(17 \%)$ & $4(7 \%)$ & 0.316 \\
\hline Nausea & $12(14 \%)$ & $4(14 \%)$ & $8(15 \%)$ & 1 \\
\hline Vomiting & $4(5 \%)$ & $2(7 \%)$ & $2(4 \%)$ & 0.912 \\
\hline Expectoration & $12(14 \%)$ & $3(10 \%)$ & $9(17 \%)$ & 0.65 \\
\hline Dizziness & $8(10 \%)$ & $2(7 \%)$ & $6(11 \%)$ & 0.818 \\
\hline Headache & $6(7 \%)$ & $1(3 \%)$ & $5(9 \%)$ & 0.596 \\
\hline Dyspnea & $11(13 \%)$ & 0 & $11(20 \%)$ & 0.007 \\
\hline Clinical Classification & & & & 0.004 \\
\hline Mild type & $16(19 \%)$ & $10(34 \%)$ & $6(11 \%)$ & \\
\hline Moderate type & $56(68 \%)$ & $19(66 \%)$ & $37(69 \%)$ & \\
\hline Severe type & $10(12 \%)$ & 0 & $10(19 \%)$ & \\
\hline Critical type & $1(1 \%)$ & 0 & $1(2 \%)$ & \\
\hline Comorbidities & $16(19 \%)$ & $2(6 \%)$ & $14(26 \%)$ & 0.036 \\
\hline Asthma & $1(1 \%)$ & $1(3 \%)$ & 0 & \\
\hline Hypertension & $5(6 \%)$ & 0 & $5(9 \%)$ & \\
\hline Diabetes & $7(8 \%)$ & 0 & $7(13 \%)$ & \\
\hline $\mathrm{NASH}^{*}$ & $2(2 \%)$ & 0 & $2(4 \%)$ & \\
\hline HBV carrier & $2(2 \%)$ & 0 & $2(4 \%)$ & \\
\hline Atherosclerosis & $2(2 \%)$ & 0 & $2(4 \%)$ & \\
\hline Others\# & $8(10 \%)$ & $1(3 \%)$ & $3(6 \%)$ & \\
\hline
\end{tabular}


*NASH: nonalcoholic steatohepatitis; \#Others: 1 child with chronic pharynitis, 1 adult had history of heart surgery, 1 adult had schizophrenia.1 adult had hypothyroidism.

\section{Difference in Laboratory and Radiographic Findings} Between Children and Adults

Blood routine test results for white blood cell count were normal in all COVID-19 children. Lymphocytopenia was not observed in children (0\%) but in 19 (35\%) adults. Blood biochemistry test result abnormality for liver function (including albumin and aminotransferase) was unremarkable among all children and adults with COVID-19. No procalcitonin elevation of more than $0.5 \mathrm{ng} / \mathrm{ml}$ was observed in children. Elevated C-reactive protein (CRP) and D-Dimer was seen in 28 (52\%) and 18 (33\%) adults, respectively. Serum creatinine was lower than $41 \mu \mathrm{mol} / \mathrm{L}$ in 20 (69\%) children and in the range of $41-81 \mu \mathrm{mol} / \mathrm{L}$ in $47(87 \%)$ adults. X-ray or chest CT showed no abnormality in 7 (24\%) children and $6(11 \%)$ adults and bilateral lung infiltration and ground-glass opacities in $13(45 \%)$ children and 42 (78\%) adults respectively (Figure1). Significant difference was observed in serum creatinine level and radiographic findings between children and adults $(\mathrm{P}=0.001)$ (Table 2).

Table 2: Laboratory and Chest imaging Findings of Patients Infected with COVID-19 on Hospital Admission.

\begin{tabular}{|c|c|c|c|c|}
\hline & All patients $(n=83)$ & Median $(I Q R)<18(n=29)$ & Median $(I Q R) \geq 18(n=54)$ & $P$ Value \\
\hline \multicolumn{5}{|l|}{ Blood routine } \\
\hline Leucocytes $\left(\times 10^{9} / \mathrm{L}\right)$ & $4.79(3.93,6.27)$ & $5.08(4.40,7.24)$ & $4.62(3.39,5.79)$ & 0.028 \\
\hline$<3.5$ & $24(29 \%)$ & $13(45 \%)$ & $11(20 \%)$ & \\
\hline $3.5-9.5$ & $57(69 \%)$ & $15(52 \%)$ & $42(78 \%)$ & \\
\hline$>9.5$ & $2(2 \%)$ & $1(3 \%)$ & $1(2 \%)$ & \\
\hline Neutrophils & $53.80(43.40,59.85)$ & $40.9(30,48.8)$ & $56.00(52.75,65.65)$ & $<0.001$ \\
\hline$<40$ & $15(18 \%)$ & $13(45 \%)$ & $2(4 \%)$ & \\
\hline $40-75$ & $66(80 \%)$ & $16(55 \%)$ & $50(92 \%)$ & \\
\hline$>75$ & $2(2 \%)$ & 0 & $2(4 \%)$ & \\
\hline Lymphocytes & $1.70(1.17,2.37)$ & $2.52(2.00,3.28)$ & $1.27(0.94,1.76)$ & $<0.001$ \\
\hline$<1.1$ & $19(23 \%)$ & 0 & $19(35 \%)$ & \\
\hline $1.1-3.2$ & $56(67 \%)$ & $21(72 \%)$ & $35(65 \%)$ & \\
\hline$>3.2$ & $8(10 \%)$ & $8(28 \%)$ & 00 & \\
\hline Platelets & $212.00(167.00,275.50)$ & $245.00(216.00,316.00)$ & $188.00(149.50,237.25)$ & 0.141 \\
\hline$<125$ & $8(10 \%)$ & $1(4 \%)$ & $7(13 \%)$ & \\
\hline $125-350$ & $67(80 \%)$ & $23(79 \%)$ & $44(81 \%)$ & \\
\hline$>350$ & $8(10 \%)$ & $5(17 \%)$ & $3(6 \%)$ & \\
\hline \multicolumn{5}{|l|}{ Blood biochemistry } \\
\hline Albumin $(\mathrm{g} / \mathrm{L})$ & $44.00(42.15,46.85)$ & $45.30(42.70,47.00)$ & $43.75(42.00,45.88)$ & 0.251 \\
\hline$<40$ & $8(10 \%)$ & $1(3 \%)$ & $7(13 \%)$ & \\
\hline $40-55$ & $75(90 \%)$ & $28(97 \%)$ & $47(87 \%)$ & \\
\hline$>55$ & 0 & 0 & 0 & \\
\hline $\begin{array}{l}\text { Alanine aminotransferase } \\
(\mathrm{U} / \mathrm{L})\end{array}$ & $19.00(12.50,29.50)$ & $16.00(11.00,25.00)$ & $20.50(14.00,30.00)$ & $>0.99$ \\
\hline $0-45$ & $79(95 \%)$ & $28(97 \%)$ & $51(94 \%)$ & \\
\hline$>45$ & $4(5 \%)$ & $1(3 \%)$ & $3(6 \%)$ & \\
\hline $\begin{array}{l}\text { Aspartate aminotransferase } \\
(\mathrm{U} / \mathrm{L})\end{array}$ & $26.00(21.00,35.50)$ & $33.00(24.00,41.00)$ & $25.00(19.00,32.50)$ & 0.232 \\
\hline $0-45$ & $76(92 \%)$ & $25(86 \%)$ & $51(94 \%)$ & \\
\hline$>45$ & $7(8 \%)$ & $4(14 \%)$ & $3(6 \%)$ & \\
\hline Urea (mmol/L) & $3.73(3.15,4.8)$ & $3.83(3.14,4.78)$ & $3.71(3.16,4.8)$ & 0.863 \\
\hline$<3.1$ & $19(23 \%)$ & $6(21 \%)$ & $13(24 \%)$ & \\
\hline $3.1-8.8$ & $63(76 \%)$ & $23(79 \%)$ & $40(74 \%)$ & \\
\hline$>8.8$ & $1(1 \%)$ & 0 & $1(2 \%)$ & \\
\hline Serum creatinine $(\mu \mathrm{mol} / \mathrm{L})$ & $53(13.3,1.08)$ & $33.5(13.3,83)$ & $63(42,108)$ & $<0.001$ \\
\hline
\end{tabular}




\begin{tabular}{|c|c|c|c|c|}
\hline$<41$ & $20(24 \%)$ & $20(69 \%)$ & 0 & \\
\hline $41-81$ & $54(65 \%)$ & $7(24 \%)$ & $47(87 \%)$ & \\
\hline$>81$ & $9(11 \%)$ & $2(7 \%)$ & $7(13 \%)$ & \\
\hline \multicolumn{5}{|l|}{$\begin{array}{l}\text { Infection-related } \\
\text { biomarkers }\end{array}$} \\
\hline Procalcitonin (ng/mL) & $0.03(0.02,0.06)$ & $0.03(0.02,0.06)$ & $0.03(0.02,0.06)$ & 0.571 \\
\hline$<0.1$ & 77 (93\%) & $26(90 \%)$ & $51(94 \%)$ & \\
\hline $0.1-0.25$ & $5(6 \%)$ & $2(7 \%)$ & $3(6 \%)$ & \\
\hline $0.25-0.5$ & $1(1 \%)$ & $1(3 \%)$ & 0 & \\
\hline$>0.5$ & 0 & 0 & 0 & \\
\hline D-Dimer (ng/mL) & $0.31(0.25,0.55)$ & $0.27(0.25,0.37)$ & $0.37(0.25,0.63)$ & 0.096 \\
\hline $0-0.5$ & $61(73 \%)$ & $25(86 \%)$ & $36(67 \%)$ & \\
\hline$>0.5$ & $22(27 \%)$ & $4(14 \%)$ & $18(33 \%)$ & \\
\hline C-reactive protein $(\mathrm{mg} / \mathrm{L})$ & $5.00(1.62,16.45)$ & $2.15(0.35,5.00)$ & $9.64(3.85,24.4 .00)$ & 0.005 \\
\hline $0-8$ & $50(60 \%)$ & $24(83 \%)$ & $26(48 \%)$ & \\
\hline$>8$ & $33(40 \%)$ & $5(17 \%)$ & $28(52 \%)$ & \\
\hline Chest imaging & & & & 0.001 \\
\hline No pneumonia & $13(16 \%)$ & $7(24 \%)$ & $6(11 \%)$ & \\
\hline Unilateral pneumonia & $13(16 \%)$ & $9(31 \%)$ & $4(7 \%)$ & \\
\hline Bilateral pneumonia & $55(66 \%)$ & $13(45 \%)$ & $42(78 \%)$ & \\
\hline Pulmonary consolidation & $2(2 \%)$ & 0 & $2(4 \%)$ & \\
\hline
\end{tabular}

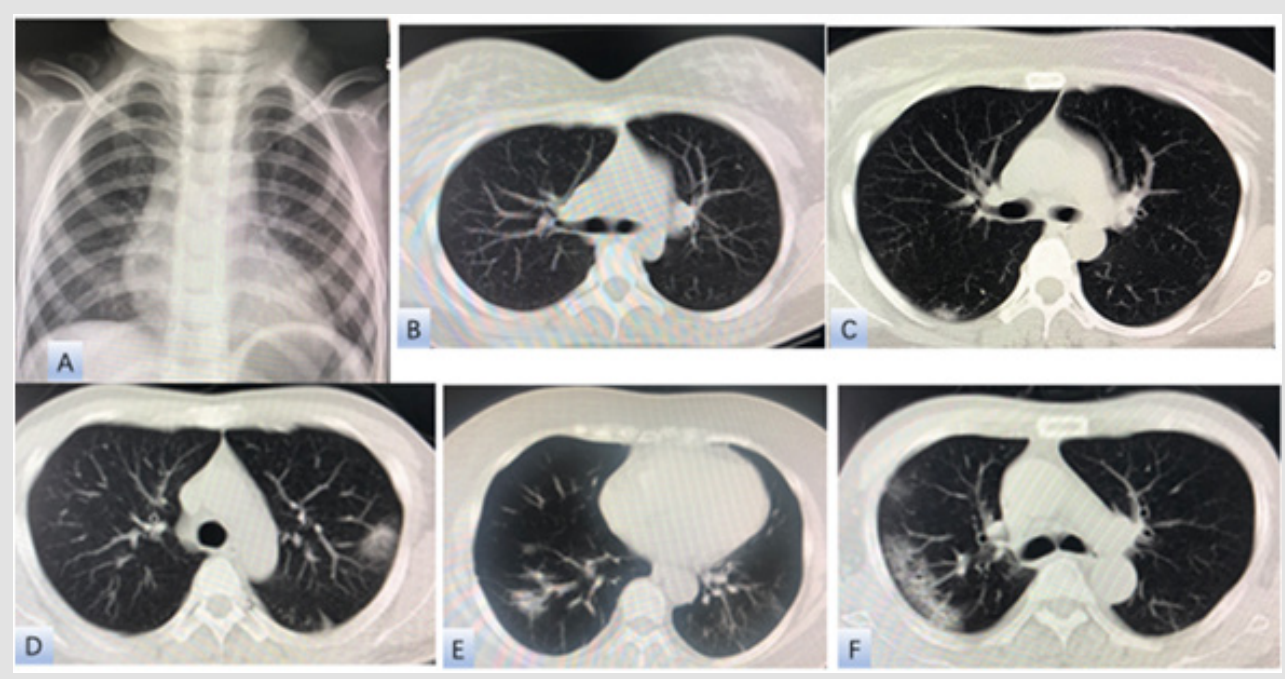

Figure 1: Chest radiographic presentation of a three-generation family in this study.

A. Chest X-ray of the 2-year-old grandson - no infiltration in both lungs; B. Chest CT of the 12-year-old granddaughter - no infiltration in both lungs; C. Chest CT of the 35-year-old mother: mild opacity in right upper lung; D. Chest CT of the 41-yearold father: mild ground-glass opacities in left lung; E. Chest CT of the 61-year-old grandmother - mild ground-glass opacities in both lower lung; F. Chest CT of the 69-year-old grandfather - patchy ground-glass opacities in the right upper lung.

\section{Difference in Treatment and Clinical Outcome Between}

\section{Children and Adults}

No administration of antibiotics, steroid or gamma globulin was needed for children. Two (4\%) adults were on antibiotics and ten (19\%) had been given immunoglobulin and methylprednisolone. No children required oxygen therapy, but 16 (30\%) adults did.
Two (4\%) adults needed intubation and mechanical ventilation, among them one died. Clinical symptoms lasted longer in adults than children. The median time from illness onset to absence of symptom was six and a half days (IQR 12.0-19.0) in children and 13 days (IQR 12.0-19.0) in adults. No therapy-associated complication was observed in children. Ten (19\%) adults had complication 
(three with ARDS, four with secondary bacterial infection and three with drug-induced hepatitis) during treatment. The average length of viral replication lasted for 12 days (IQR 5-21) in children and 14 days (IQR 3-35) in adults. The median time from hospital admission to discharge was 17 days (IQR 7-31) for children and 21 days (IQR 3-48) for adults. Despite one fatality, all patients were discharged when this manuscript was being prepared (Table 3).

Table 3: Treatment and outcome of patients with COVID-19 in Shenzhen, China.

\begin{tabular}{|c|c|c|c|c|}
\hline & \multicolumn{3}{|c|}{ Age groups (years): } & \multirow{2}{*}{ P Value } \\
\hline & All $(n=83)$ & $<18(n=29)$ & $\geq 18(n=54)$ & \\
\hline \multicolumn{5}{|l|}{ Treatment and outcome } \\
\hline \multicolumn{5}{|l|}{ Treatment } \\
\hline Oxygen therapy & $16(30 \%)$ & 0 & $16(30 \%)$ & 0.001 \\
\hline Mechanical intervention & $2(2 \%)$ & 0 & $2(4 \%)$ & 0.54 \\
\hline Antibiotics therapy & $2(2 \%)$ & 0 & $2(4 \%)$ & 0.54 \\
\hline Corticosteroid and gamma globulin & $10(12 \%)$ & 0 & $10(19 \%)$ & 0.013 \\
\hline Complications & $10(12 \%)$ & 0 & $10(19 \%)$ & 0.0126 \\
\hline ARDS & $3(4 \%)$ & 0 & $3(6 \%)$ & \\
\hline Secondary bacterial pneumonia & $4(5 \%)$ & 0 & $4(7 \%)$ & \\
\hline Drug-induced hepatitis & $3(4 \%)$ & 0 & $3(6 \%)$ & \\
\hline Acute kidney injury & $1(1 \%)$ & 0 & $1(2 \%)$ & \\
\hline Septic shock & $1(1 \%)$ & 0 & $1(2 \%)$ & \\
\hline Venous thrombus & $1(1 \%)$ & 0 & $1(2 \%)$ & \\
\hline Duration of virus replication & $13(3-35)$ & $12(5-2)$ & $14(3-35)$ & 0.0357 \\
\hline $\begin{array}{l}\text { Time from illness onset to absence of } \\
\text { symptom }\end{array}$ & $11(1-72)$ & $6.5(1-33)$ & $13(2-72)$ & 0.0014 \\
\hline $\begin{array}{c}\text { Time from hospital admission to } \\
\text { discharge }\end{array}$ & $21(3-51)$ & $17(7-31)$ & $23(3-51)$ & 0.016 \\
\hline Treatment outcome & & & & 1 \\
\hline Cured & $82(98 \%)$ & $29(100 \%)$ & $53(98 \%)$ & \\
\hline Death & $1(1 \%)$ & $0(0.0 \%)$ & $1(2 \%)$ & \\
\hline
\end{tabular}

\section{Discussion}

Six species of human coronavirus ( $\mathrm{HCoV}$ ) have been reported to cause infection in human: OC43, 229E, SARS, NL63, HKU1, and MERS [11]. Same as severe acute respiratory syndrome coronavirus (SARS-CoV) and Middle East respiratory syndrome coronavirus (MERS-CoV), definite person-to-person transmission of the novel coronavirus 2019 in hospital and family settings had been confirmed $[7,12,13]$. Transmission was most likely airborne via aerosol and respiratory droplets through close contact with infected individuals or exposure to the epidemic area. The clinical spectrum of COVID-19 varied from asymptomatic infection to viral pneumonia with acute respiratory distress syndrome (ARDS). Previous studies suggested that SARS-CoV-2 was less likely to infect children [14-16]. There were only a small number of confirmed cases in children compared to adults, even in the epicenter at the time of disease outbreak [5,6]. Most documented literature showed that a substantial proportion of children with COVID-19 were either asymptomatic or only manifested mild fever and prominent upper respiratory tract symptoms with a much lower mortality rate than adults [17]. Progression to respiratory or organ failure and death cases were rare but had been reported in China as early as February and other places of the world afterwards [18].

In our study, all pediatric patients acquainted COVID-19 through family infection. Contact tracing showed a rather straightforward infection source with $83 \%$ children and $84 \%$ of the enrolled patients in this study reported Hubei-related exposure 2 weeks before the onset of symptoms. But in contrast to adults, clinical symptoms of pediatrics were mild, even among those with underlying comorbidities (chronic pharyngitis and asthma). Viral pneumonia indicated by mild ground-glass opacities in bilateral lungs were observed in 45\% (13) children. None of them progressed to ARDS or other complications. This was like other HCoV infection in children $[2,3,19]$. The lack of prominent clinical symptoms on disease onset in pediatric patients suggests that they could be a threat in the transmission chain which is a crucial concern in disease management regimen designs.

Older age has been reported a risk factor for mortality in patients with SARS, MERS and COVID-19 in several studies [20,21]. Pathological finding from biopsy of COVID-19 patients showed massive alveolar damage with ARDS [22]. Excessive and aberrant 
non-effective immune response induced by cytokine storm might lead to severe organ injury in adults with COVID-19. In a household infection of 3 generations in this study, chest imaging exhibited bilateral ground-glass opacities in the oldest generation, with the oldest male patient progressed to ARDS, but the two adults in the mid generation only exhibited minor viral pneumonia symptoms, and the youngest generation showed no abnormality in their radiographic presentation (Figure1). The age-distinct immune difference may have explained the divergence in inflammatory responses in control of viral replication of SARS-CoV-2 between children and adults.

Immune over reaction and T cell exhaustion were demonstrated in patients with sepsis and other life-threatening infections [23]. Lymphopenia is an important sign of $\mathrm{T}$ cell exhaustion [24]. Progressive lymphopenia had been reported a risk factor for Intensive Care Unit admission and mortality of adult patients with COVID-19[13,21]. Progressive drop in lymphocyte count was obvious in patients with severe and critical clinical types. In the case of the deceased patient in this study, progressive lymphopenia had been recorded since the patient was hospitalized. The patient's clinical conditions deteriorated rapidly with an acute progression to ARDS. Even with invasive mechanical ventilation the patient still failed treatment and died. Our study showed that lymphocyte count between children and adult differed significantly, despite the physiological difference. None of the children but 35\% adults exhibited lymphopenia. This might attribute to the prolonged illness and viral shedding in adults. In addition, some inflammationrelated biomarker such as CRP and D-Dimer elevated in adults but not in children during the treatment process. D-dimer greater than $1 \mu \mathrm{g} / \mathrm{ml}$ at early stage of illness onset had been identified with poor prognosis in adults [21]. The level and duration of viral replication on the upper respiratory tract are vital factors in assessing the risk of transmission. A study reported that detectable SARS-CoV-2 RNA persisted for a median duration of 20 days in adults infected with COVID-19 and sustained until death of the host cell in non-survivors [21]. In the current study, the length of viral replication also lasted longer in adults than children (14 days vs 12 days). Though certain medications demonstrated effective treatment outcome [25-27], no specific antiviral medications have been proven to be effective in clinical trials for this novel coronavirus infection as of to date.

Our study has some limitations. First, no complete genotype was available for every family. The transmission model of the virus in the families was not clear, whether children or adults were the source of transmission was difficult to determine. Second, this is a modest-sized case series of children and their family admitted to a single center. As all children had mild symptoms, it is difficult to take blood test frequently to assess their immune reaction at different time points. Third, how antibody titers changed during the clinical course in all these patients was not available. More effort should be made to address these areas in future studies.Observing from our study, children are equally susceptible to contracting COVID-19 as adults, but pediatric patients had milder symptoms, less immunerelated organ injury and shorter viral replication cycle than adults when being infected. More medical attention could be diverted to elderly patients and patients with pre-existing medical conditions to decrease fatality especially in places with shortage in medical resources. In the absence of specific therapeutic drugs or vaccines for COVID-19, we believe it is noteworthy to find out the potential correlation between different age specific immune state for hostdirected interventions to improve treatment outcomes in adults.

\section{Acknowledgement}

The authors would like to thank Professor Feng Yin for the valuable advice and enthusiastic encouragement on the design and writing of this study.

\section{Conflict of Interest}

The authors have no conflicts relevant to the content of the article or financial interest to declare.

\section{Funding Source}

This work was supported financially by the 13th Five-Year Major Projects of National Science and Technology of China (2018ZX10715004-002-007) and Science Research Fund of Guang dong Province (B2018045).

\section{Availability of Data and Materials}

The data sets used and/or analyzed in this study are available from the corresponding author on reasonable request.

\section{Ethics Approval and Consent to Participate}

The study was approved by the Research Ethics Commission of The Third People's Hospital of Shenzhen (No.2020-120) and the requirement for informed consent was waived by the Ethics Commission as part of a public health outbreak investigation.

\section{Consent for Publication}

No individual or identifiable persons' details are included in this manuscript.

\section{References}

1. Zhu N, Zhang D, Wang W, Li X, Yang B, et al. (2020) A Novel Coronavirus from Patients with Pneumonia in China, 2019. N Engl J Med 382(8): 727733.

2. Ogimi C, Englund JA, Bradford MC, Qin X, Boeckh M, et al. (2019) Characteristics and Outcomes of Coronavirus Infection in Children: The Role of Viral Factors and an Immunocompromised State. J Pediatric Infect Dis Soc 8(1): 21-28.

3. Heimdal I, Moe N, Krokstad S, Christensen A, Skanke LH, et al. (2019) Human Coronavirus in Hospitalized Children With Respiratory Tract Infections: A 9-Year Population-Based Study From Norway. J Infect Dis 219(8): 1198-1206.

4. Bartenfeld M, Griese S, Uyeki T, Gerber SI, Peacock G (2017) Middle East Respiratory Syndrome Coronavirus and Children. Clin Pediatr (Phila) 56(2): 187-189.

5. Wei M, Yuan J, Liu Y, Fu T, Yu X, et al. (2020) Novel Coronavirus Infection in Hospitalized Infants Under 1 Year of Age in China. JAMA 323(13): $1313-1314$ 
6. Liu W, Zhang Q Chen J, Xiang R, Song H, et al. (2020) Detection of Covid-19 in Children in Early January 2020 in Wuhan, China. N Engl J Med 382(14): 1370-1371.

7. Chan JF, Yuan S, Kok KH, To KK, Chu H, et al. (2020) A familial cluster of pneumonia associated with the 2019 novel coronavirus indicating person-to-person transmission: a study of a family cluster. Lancet 395(10223): 514-523.

8. Sun D, Li H, Lu XX, Xiao H, Ren J, et al. (2020) Clinical features of severe pediatric patients with coronavirus disease 2019 in Wuhan: a single center's observational study. World J Pediatr 16(3): 251-259.

9. https://peoplepill.com/people/sheng-zhen/

10. (2020) National Health Commission of the People's Republic of China Chinese management guideline for COVID-19.

11. Paules CI, Marston HD, Fauci AS (2020) Coronavirus Infections-More Than Just the Common Cold. JAMA.

12. Li Q, Guan X, Wu P, Wang X, Zhou L, et al. (2020) Early Transmission Dynamics in Wuhan, China, of Novel Coronavirus-Infected Pneumonia. New England Journal of Medicine 382(13): 1199-1207.

13. Huang C, Wang Y, Li X, Ren L, Zhao J, et al. (2020) Clinical features of patients infected with 2019 novel coronavirus in Wuhan, China. Lancet 395(10223): 497-506.

14. Chen N, Zhou M, Dong X, Qu J, Gong F, et al. (2020) Epidemiological and clinical characteristics of 99 cases of 2019 novel coronavirus pneumonia in Wuhan, China: a descriptive study. Lancet 395(10223): 507-513.

15. Wang D, Hu B, Hu C, Zhu F, Liu X, et al. (2020) Clinical Characteristics of 138 Hospitalized Patients With 2019 Novel Coronavirus-Infected Pneumonia in Wuhan, China. JAMA 323(11): 1061-1069.

16. Guan WJ, Ni ZY, Hu Y, Liang WH, Ou CQ et al. (2020) Clinical Characteristics of Coronavirus Disease 2019 in China. N Engl J Med.

ISSN: 2574-1241

DOI: $10.26717 /$ BJSTR.2020.30.004977

Guofang Deng. Biomed J Sci \& Tech Res

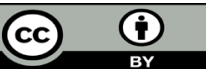

This work is licensed under Creative Commons Attribution 4.0 License

Submission Link: https://biomedres.us/submit-manuscript.php
17. Sinha IP, Harwood R, Semple MG, Hawcutt DB, Thursfield R, et al. (2020) COVID-19 infection in children. The Lancet Respiratory Medicine 8(5): 446-447.

18. Dong Y, Mo X, Hu Y, Qi X, Jiang F, et al. (2020) Epidemiology of COVID-19 Among Children in China. Pediatrics 145(6): e20200702.

19. Thabet F, Chehab M, Bafaqih H, Al Mohaimeed S (2015) Middle East respiratory syndrome coronavirus in children. Saudi Med J 36(4): 484 486

20. Milne-Price S, Miazgowicz KL, Munster VJ (2014) The emergence of the Middle East respiratory syndrome coronavirus. Pathog Dis 71(2): 121136.

21. Zhou F, Yu T, Du R, Fan G, Liu Y, et al. (2020) Clinical course and risk factors for mortality of adult inpatients with COVID-19 in Wuhan, China: a retrospective cohort study. The Lancet 395(10229): 1054-1062.

22. Xu Z, Shi L, Wang Y, Zhang J, Huang L, et al. (2020) Pathological findings of COVID-19 associated with acute respiratory distress syndrome. The Lancet Respiratory Medicine 8(4): 420-422.

23. Wherry EJ (2011) T cell exhaustion. Nat Immunol 12(6): 492-499.

24. Wherry EJ, Kurachi M (2015) Molecular and cellular insights into T cell exhaustion. Nat Rev Immunol 15(8): 486-499.

25. Holshue ML, DeBolt C, Lindquist S, Lofy KH, Wiesman J, et al. (2020) First Case of 2019 Novel Coronavirus in the United States. N Engl J Med 382(10): 929-936.

26. Wang M, Cao R, Zhang L, Yang X, Liu J, et al. (2020) Remdesivir and chloroquine effectively inhibit the recently emerged novel coronavirus (2019-nCoV) in vitro. Cell Research 30(3): 269-271.

27. Richardson P, Griffin I, Tucker C, Smith D, Oechsle O, et al. (2020) Baricitinib as potential treatment for 2019-nCoV acute respiratory disease. The Lancet 395(10223): e30-e31.

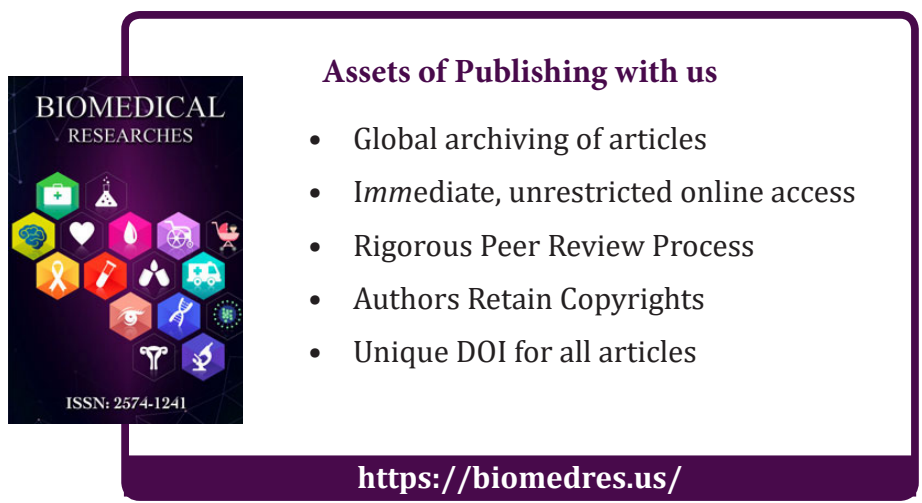

